\title{
Bilateral Tinea Nigra Plantaris with Good Response to Isoconazole Cream: A Case Report
}

\author{
Eduardo Mastrangelo Marinho Falcão ${ }^{a} \quad$ Beatriz Moritz Trope ${ }^{a}$ \\ Natália Regina Pinto Guedes Martins ${ }^{a}$ \\ Maria da Glória Carvalho Barreiros ${ }^{\mathrm{b}} \quad$ Marcia Ramos-e-Silva ${ }^{\mathrm{a}}$ \\ ${ }^{a}$ Sector of Dermatology, and ${ }^{b}$ Mycology Laboratory, University Hospital and School of \\ Medicine, Federal University of Rio de Janeiro, Rio de Janeiro, Brazil
}

\section{Key Words}

Tinea nigra $\cdot$ Hortaea werneckii $\cdot$ Mycoses

\begin{abstract}
Tinea nigra is a superficial fungal infection caused by Hortaea werneckii. It typically affects young individuals as an asymptomatic unilateral macule, from light brown to black on the palms and soles, mainly in tropical and subtropical regions. In 1997, Gupta et al. [Br J Dermatol 1997;137:483-484] described the dermoscopic characteristics of tinea nigra. Topical antifungals with or without keratolytic agents can be used for the treatment. The authors report a case of a 47-year-old man with asymptomatic light brown macules bilaterally on the plantar regions. Dermoscopic examination revealed brownish spicules consistent with the pattern described in the literature. Treatment with isoconazole cream was effective with complete resolution.

(C) 2015 The Author(s) Published by S. Karger AG, Basel
\end{abstract}

\section{Introduction}

Tinea nigra, a rare superficial phaeohyphomycosis, was observed for the first time in Brazil, by Alexandre Cerqueira, in 1891 [1]. Its etiologic agent is nowadays called Hortaea werneckii [2] and occurs in regions with tropical and subtropical climate, mainly in areas with high salt concentration. The characteristic lesion is a unilateral and asymptomatic macule, with color varying from brown to black, with well-demarked limits, and differential di- 
Falcão et al.: Bilateral Tinea Nigra Plantaris with Good Response to Isoconazole Cream: A Case Report

agnosis with melanocytic lesions. It is observed in young individuals, affecting palmar and with less frequency plantar regions [3].

\section{Case Report}

A 47-year-old man, resident in Rio de Janeiro, musician, previously diagnosed with vitiligo, was referred with dark, asymptomatic spots, bilaterally in the plantar region, about a year ago. He informed partial improvement after abrasion with sandpaper. He denied a temporal relation between contact with beach sand and the appearance of the lesions.

Upon examination, light brown macules with well-defined borders without scaling were noticeable ( 3 on the right plantar region, with $2.0,2.5$ and $3.0 \mathrm{~cm}$ in their largest diameter, and 1 on the left, with $2.5 \mathrm{~cm}$; fig. 1, fig. 2). The dermoscopic examination of the lesions showed a homogeneous, nonmelanocytic pattern with some brownish spikes (fig. 3). In addition to these lesions, achromic macules on the back of his hands and on the penis were present, compatible with vitiligo.

The scraped material from the feet lesions was submitted to direct examination, which revealed septate hyphae of brownish coloration (fig. 4). Sabouraud agar cultivation revealed a wet, filamentous and black colony, typical features of Hortaea werneckii, confirming the diagnosis of tinea nigra (fig. 5). Treatment with isoconazole cream twice a day for 20 days was effective, with complete resolution of the plantar lesions and no recurrence after 6 months of follow-up.

\section{Discussion}

Tinea nigra is a fungal infection that only affects the stratum corneum, first observed by the Brazilian Alexandre Cerqueira and later described in 1916 by his son, Antonio Cerqueira, as keratomycosis nigricans palmaris [1].

In 1921, Horta [4] isolated the etiologic agent by naming it Cladosporium werneckii. Later, it was renamed Exophiala werneckii, Phaeoannellomyces werneckii [3] and, currently, Hortaea werneckii. There are reports caused by other agents such as Scopulariopsis brevicaulis, Phoma eupyrena and Chaetomium globosu [2] and in Venezuela, the indigenous fungus Stenella araguata [5].

The typical clinical picture is characterized by single, unilateral and asymptomatic macules, light brown to black, with sharp borders. It affects the palmoplantar region, particularly the palms and palmar aspect of the fingers, and is more prevalent in women under 20 years [3].

Hortaea werneckii is a dematiaceous fungus found in tropical and subtropical climates. Its presence was confirmed in areas of high salt concentration, with beach sand being a possible source of contamination $[2,3,6]$. The direct mycological examination reveals brown, septate hyphae with thick walls. In culture, black, humid and shiny colonies are found [2, 3].

In 1997, Gupta et al. [7] described the typical dermoscopic aspect of tinea nigra, with pigmented spicules forming a homogeneous, almost reticular aspect. Other authors emphasized that pattern and the use of dermoscopy in the differential diagnosis with melanocytic lesions $[8,9]$. The dermoscopic examination of our patient's stains revealed pigmented spicules arranged in a pattern similar to that described in those publications.

Although effective, systemic treatment is not necessary [7]. Keratolytic agents alone and topical antifungal agents, such as imidazole derivatives, terbinafine or ciclopirox, whether or 


\section{Case Reports in \\ Dermatology}

\begin{tabular}{l|l}
\hline Case Rep Dermatol 2015;7:306-310 \\
\hline DOI: $10.1159 / 000441602$ & $\begin{array}{l}\text { (c) 2015 The Author(s). Published by S. Karger AG, Basel } \\
\text { www.karger.com/cde }\end{array}$ \\
\hline
\end{tabular}

Falcão et al.: Bilateral Tinea Nigra Plantaris with Good Response to Isoconazole Cream: A Case Report

not associated with keratolytic agents, can be used [10]. Moreover, there are reports of spontaneous healing [6].

We emphasize our patient's atypical presentation, with a bilateral involvement of plantar regions, and the importance of the use of dermoscopy as a low-cost diagnostic tool, reducing the need for invasive procedures. We still emphasize the rapid and complete therapeutic response to topic isoconazole, in accordance with the literature.

\section{Statement of Ethics}

The authors have no ethical conflicts to disclose.

\section{Disclosure Statement}

The authors declare no conflicts of interest. No funding was obtained for this work.

\section{References}

1 Cerqueira AG: Keratomycosis nigricans palmaris [Thesis]. Salvador, Bahia, Brazil: Faculdade de Medicina da Bahia [School of Medicine]. 1916.

2 Revankar SG, Sutton DA: Melanized fungi in human disease. Clin Microbiol Rev 2010;23:884-928.

3 Marques AS, Camargo RMP: Tinea nigra: relato de caso e revisão da literatura brasileira. An Bras Dermatol 1996;71:431-435.

4 Horta P: Sobre um caso de tinha preta e um novo cogumelo (Cladosporium werneckii). Ver Med Cir Brasil 1921;29:269-274.

5 Perez C, Colella MT, Olaizola C, Hartung de Capriles C, Magaldi S, Mata-Essayag S: Tinea nigra: report of twelve cases in Venezuela. Mycopathologia 2005;160:235-238.

6 Rossetto AL, Cruz RC: Cura espontânea em um caso de tinea nigra. An Bras Dermatol 2012;87:160-162.

-7 Gupta G, Burden AD, Shankland GS, Fallowfield ME, Richardson MD: Tinea nigra secondary to Exophiala werneckii responding to itraconazole. Br J Dermatol 1997;137:483-484.

8 Criado PR, Delgado L, Alonso G: Dermoscopy revealing a case of tinea nigra. An Bras Dermatol 2013;88:128129.

-9 Xavier MH, Ribeiro LH, Duarte H, Saraça G, Souza AC: Dermatoscopy in the diagnosis of tinea nigra. Dermatol Online J 2008;14:15.

10 Almeida HL Jr: Tratamento bem-sucedido de Tinea nigra palmaris com terbinafina tópica. An Bras Dermatol 2000;75:639-640. 


\section{Case Reports in \\ Dermatology}

\begin{tabular}{l|l}
\hline Case Rep Dermatol 2015;7:306-310 \\
\hline DOI: 10.1159/000441602 & $\begin{array}{l}\text { (c) 2015 The Author(s). Published by S. Karger AG, Basel } \\
\text { www.karger.com/cde }\end{array}$ \\
\hline
\end{tabular}

Falcão et al.: Bilateral Tinea Nigra Plantaris with Good Response to Isoconazole Cream: A Case Report

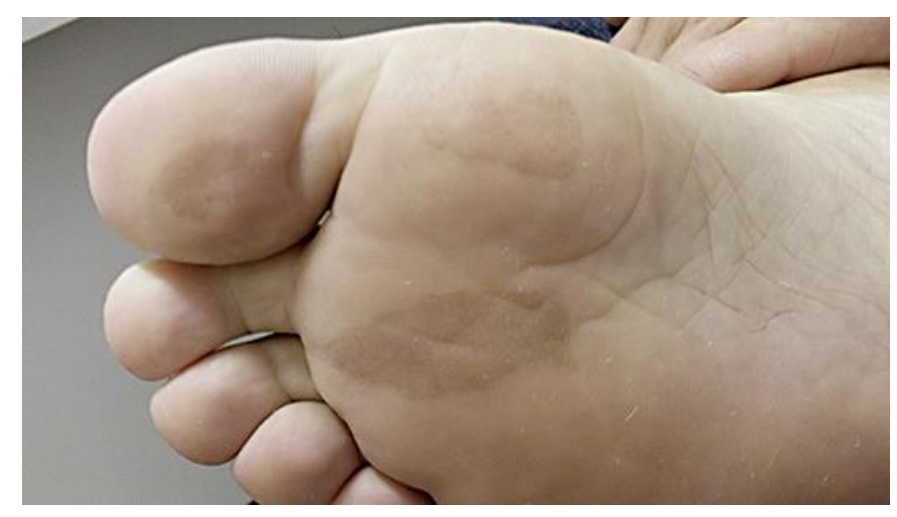

Fig. 1. Macules of light brown color on the plantar region of the foot and halux.

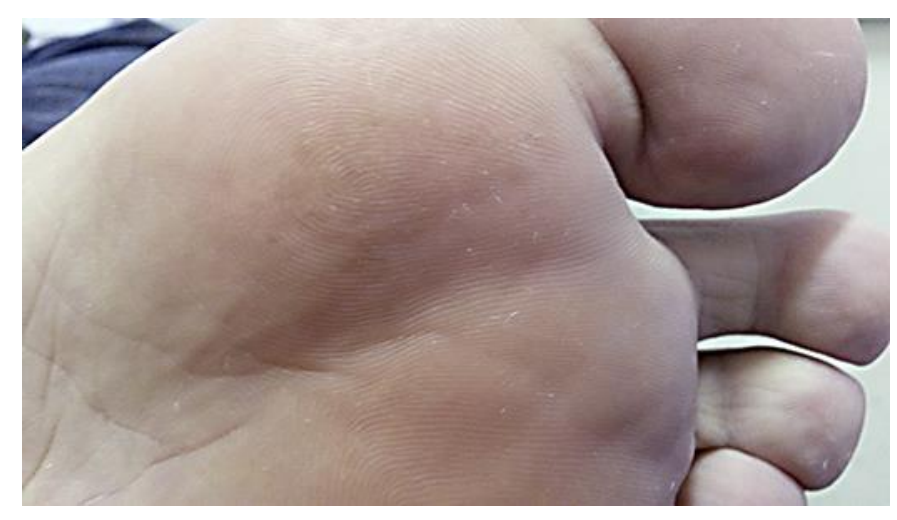

Fig. 2. Macule of light brown color in the left plantar region.

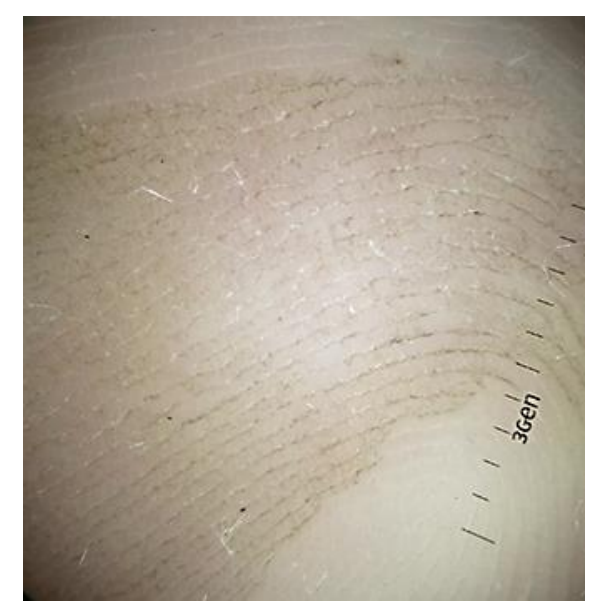

Fig. 3. Pigmented spicules forming an almost reticular aspect (dermoscopy, X10). 
Falcão et al.: Bilateral Tinea Nigra Plantaris with Good Response to Isoconazole Cream: A Case Report

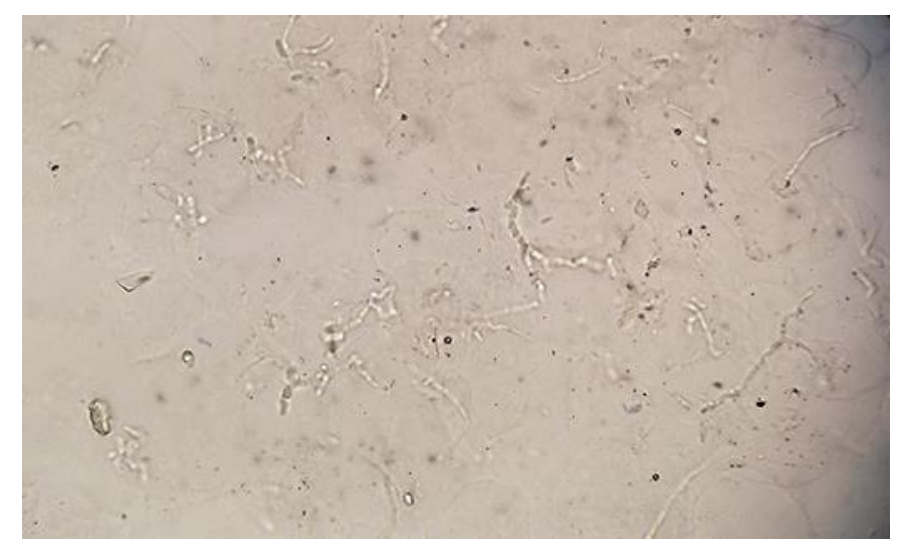

Fig. 4. Septated hyphae with thick walls and brownish color.

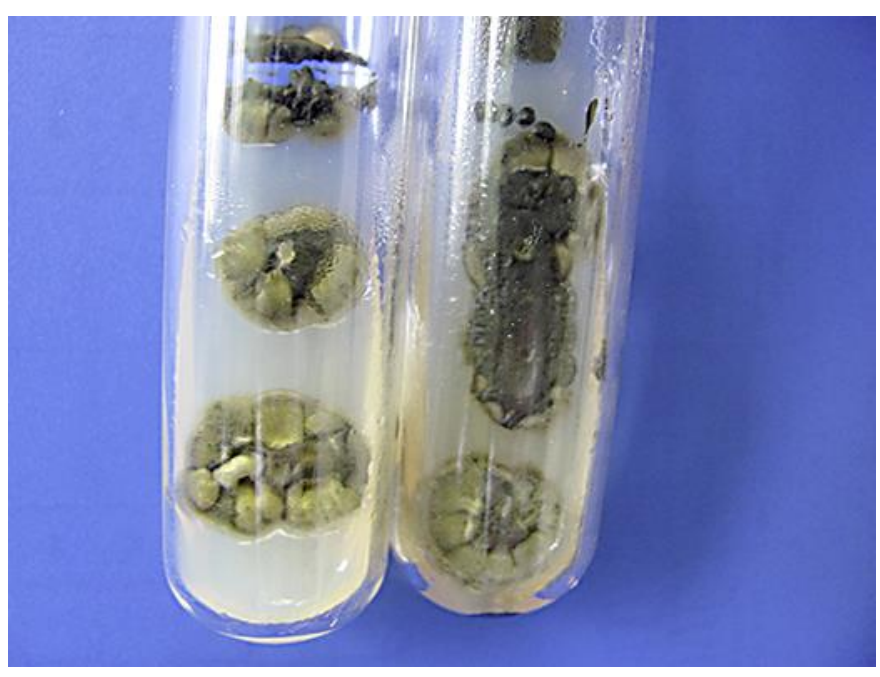

Fig. 5. Humid and black colonies of Hortaea werneckii. 